\title{
On the distribution of formaldehyde in the western Po-Valley, Italy, during FORMAT 2002/2003
}

\author{
W. Junkermann \\ Karlsruhe Institut of Technology, Institute for Meteorology and Climate Research, IMK-IFU, Kreuzeckbahnstr. 19, \\ 82467 Garmisch-Partenkirchen, Germany
}

Received: 30 April 2009 - Published in Atmos. Chem. Phys. Discuss.: 26 June 2009

Revised: 21 October 2009 - Accepted: 10 November 2009 - Published: 7 December 2009

\begin{abstract}
Formaldehyde was measured in the area of Milano, Italy, during the 2002 and 2003 FORMAT campaigns at three ground field sites and from an ultralight aircraft. The horizontal distributions show a strong impact of local emissions at a site in the centre of Milano and more photochemically driven diurnal patterns in the remote locations north and south of the city. The mixing ratios in the agricultural areas upwind of Milano were comparable to those downwind indicating the importance of biogenic emissions and anthropogenic agricultural activities. The vertical distributions were dominated by transport processes with advection of $\mathrm{CH}_{2} \mathrm{O}$ above the planetary boundary layer by cloud venting. Comparison to previously published model calculations, based on part of the data set, show discrepancies both, in the diurnal patterns and in the regional distribution which allude to uncertainties in emission inventories.
\end{abstract}

\section{Introduction}

Formaldehyde, HCHO, is one of the key substances in the photochemical production of radicals and of secondary photochemical compounds. HCHO is a product within the oxidation chain of $\mathrm{CH}_{4}$ in the atmosphere producing a background level of $\mathrm{HCHO}$ of the order of about $0.5 \mathrm{ppb}$ (Junkermann and Stockwell, 1999). It is also a secondary product of biogenic precursors or direct traffic and industrial emissions. In remote areas, mixing ratios of $\mathrm{HCHO}$ typically are below a few ppb and they are strongly correlated with the local advection of polluted air masses (Stockwell et al., 1996; Slemr et al., 1993). In polluted environments, mixing ratios may reach more than $30 \mathrm{ppb}$. Most of these immissions come either directly from fossil fuel burning or from secondary reactions in

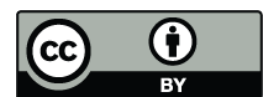

Correspondence to: W. Junkermann (wolfgang.junkermann@kit.edu) the atmosphere during degradation of different VOC's (Possanzini et al., 2002; Garcia et al., 2006). Under polluted conditions, HCHO serves as one of the main sources for radicals in the atmosphere, exceeding occasionally radical production from ozone photolysis by up to an order of magnitude (Kleinmann, 1996; Possanzini et al., 2002). Additional formaldehyde in the environment thus has a boosting effect on air chemistry. In higher concentrations HCHO is a toxic compound. Within the outdoor environment even in polluted situations the levels normally do not exceed the health critical values. Maximum values reported are about $50 \mathrm{ppb}$ (Grosjean et al., 1996; Eom et al., 2008). As formaldehyde is a very ubiquitous substance and has a strong impact on the photochemistry of polluted areas, the European Community Project FORMAT has been launched to investigate the three dimensional distribution and the diurnal patterns of formaldehyde mixing ratios in an area with high levels of pollution, the region of Milano in the Italian Po-Valley, which is one of the most polluted areas in Europe. Two campaigns were performed: in 2002 from the end of July until 19 August and in 2003 from 10 September to 3 October. The project also included a comparison of different in situ and remote sensing techniques for the measurement of formaldehyde under natural conditions in a moderate to highly polluted site in the first week of the 2002 campaign. This comparison experiment and its results are described in detail by Hak et al. (2005). A later instrument comparison using a smog chamber can be found in Wisthaler et al. (2008). In both intercomparisons the in situ instruments used in this study performed well. Final absolute calibration issues, as discussed in Hak et al. (2005), could be solved and are considered in the data presented here. Following the comparison exercise, the participating instruments were distributed to three field sites. Assuming, that a city plume could be detectable during high pressure situations, the sites were selected upwind (south of Pavia), downwind (Alzate) and close to the center (Bresso) of the City of Milano. Airborne measurements were

Published by Copernicus Publications on behalf of the European Geosciences Union. 
performed using two instrumented aircraft, an ultralight research aircraft (Junkermann, 2001) and a motorized glider (METAIR) for measurements of vertical and horizontal distributions. Both were carrying an online measuring Hantzsch instrument (Junkermann and Burger, 2006). An additional Partenavia PA68 was equipped with a MAX-DOAS remote sensing system for the investigation of $\mathrm{HCHO}, \mathrm{SO}_{2}$ and $\mathrm{NO}_{2}$ (Wang et al., 2006). Anthropogenic and biogenic VOC's were measured at the two field sites Alzate and Bresso (Steinbacher et al., 2005a, b) while the ground based DOAS instruments measured also $\mathrm{O}_{3}$ and $\mathrm{NO}_{2}$. Only the measurements from the Hantzsch technique installed on ground and the microlight aircraft are presented here. Some of the data were already presented in two publications by Liu et al. (2007a, b). Vertical distributions presented in this manuscript as well as data from the additional field sites south of Milano complete the published experimental data set. Beyond the modelling work in Liu et al. (2007a, b) further details concerning the agreement between experiments and model simulations are presented here. This includes the description of typical diurnal patterns, deviations from the model temporal and spatial patterns, as well as the differences in vertical distributions.

\section{Experimental}

$\mathrm{HCHO}$ measurements described in this paper were performed using the continuous Hantzsch technique by the stripping of $\mathrm{HCHO}$ into a slightly acidic solution, followed by liquid phase fluorimetric detection (Junkermann and Burger, 2006). The technique is also the basis for a commercial instrument (AERO-LASER, Model 4001) used for the ground based investigations. Three of these instruments, all running from the same batch of chemistry, were employed at ground stations for continuous monitoring about two meters above ground. All instruments were operated using internal gas phase calibration sources once per day and an internal zeroing cycle four times a day. Instruments were regularly calibrated using a liquid phase travelling standard. These additional liquid calibrations were performed at a minimum of three times a week. All operating solutions were stored at $4^{\circ} \mathrm{C}$ in the field. Inlet lines for all instruments were made from $1 / 4^{\prime \prime}, 4 \mathrm{~mm}$ inner diameter, PFA tubing with a length of $10 \mathrm{~m}$. At the inlet of these lines a $47 \mathrm{~mm}$ PFA in-line filter was installed to keep the inlet line clean. This filter was replaced once a day. The procedure, adapted also for shipborne measurements (Stockwell and Junkermann, 1996) and highly polluted situations in Mexico City (de Gouw et al., 2009), avoids any losses in the inlet lines larger than $3 \%$. The detection limit for the instruments was estimated in the laboratory to be below $30 \mathrm{ppt}(3 \sigma)$. Though stored in shelters, the commercial instruments were subject to ambient temperature changes during the campaign and were not fully compensated for such field conditions. Thus for the field experiment, a detection limit of $<100 \mathrm{ppt}(3 \sigma)$ was estimated based on baseline and sensitivity drift within the $6 \mathrm{~h}$ zeroing intervals.

All ground based instruments were operated for more than three weeks in each of the two campaigns from 26 July to 19 August 2002 and from 12 September to 3 October 2003 in the north, the city and the south of Milano, the biggest source of anthropogenic pollution in the Po-Valley. The northern station Alzate $\left(45^{\circ} 46^{\prime} 10^{\prime \prime} \mathrm{N}, 9^{\circ} 9^{\prime} 40^{\prime \prime} \mathrm{E}, 385 \mathrm{~m}\right.$ a.s.l.) and the city station Bresso ( $45^{\circ} 32^{\prime} 24^{\prime \prime} \mathrm{N}, 9^{\circ} 12^{\prime} 06^{\prime \prime} \mathrm{E}, 146 \mathrm{~m}$ a.s.l.) were installed at the same location during both campaigns. However the southern site was moved for the 2003 experiment by $\sim 30 \mathrm{~km}$ from the site for 2002, Cascina Casinazza, $\left(45^{\circ} 02^{\prime} 35^{\prime \prime} \mathrm{N}, 8^{\circ} 58^{\prime} 45^{\prime \prime} \mathrm{E}, 75 \mathrm{~m}\right.$ a.s.l.), to the airfield of Spessa $\left(45^{\circ} 7^{\prime} 40^{\prime \prime} \mathrm{N}, 9^{\circ} 21^{\prime} 35^{\prime \prime} \mathrm{E}, 66 \mathrm{~m}\right.$ a.s.l.) due to simpler logistics and easier access. Figure 1 shows a map of the area including airspace signatures, motorways (double lines) and urban regions (yellow).

Airborne measurements of $\mathrm{HCHO}$ were performed using the modified version of the Hantzsch instrument described in detail in Junkermann and Burger (2006). The instrument was installed on a microlight aircraft (Junkermann, 2001). The instrument, stripped down in weight to $2.5 \mathrm{~kg}$, has a slightly higher detection limit of $50 \mathrm{ppt}$ compared to the commercial version. Several measures to increase the temperature stability resulted in the same $100 \mathrm{ppt}$ field detection limit during the airborne application although the instrument was operated in a wider temperature range and was subject to temperature changes of $>20^{\circ} \mathrm{C}$ within 15 min during vertical profile flights. The main improvement could be achieved by miniaturization and temperature stabilization of the fluorescence detector and the replacement of the mercury lamp by a temperature stabilized LED. Also, internal liquid lines were kept as short and as thin as possible. Zeroing was done manually dependent on the flight pattern, so as to not disturb data collection during vertical soundings. Liquid phase calibrations were performed before and after each flight.

Flights were flown on 10 days, based out of the airfield of Lecco Monte Marenzo in the northeast of Milano, in 2002 and for 7 days, based out of the airfield of Spessa, south of Milano, in 2003. The choice of Spessa allowed the operation of the aircraft and one of the ground stations at one location and avoided the vicinity of the mountainous area of Lecco, a region affected by frequent afternoon local thunderstorms.

Additional instrumentation on the aircraft included actinic radiation, corresponding to the photolysis rates $J^{1} \mathrm{D}$ at $300 \mathrm{~nm}$ and $J \mathrm{NO}_{2}$ at $380 \mathrm{~nm}$, visibility, ozone mixing ratio, temperature and dewpoint and aerosol size and number instrumentation. Several of these parameters can be used to characterize the air masses and to define the planetary boundary layer during vertical profile flight patterns. The distribution of aerosols into the fine fraction $(>300 \mathrm{~nm})$ and the ultrafine particles $(>10 \mathrm{~nm})$ can be used as an indicator of different pollution scenarios. 


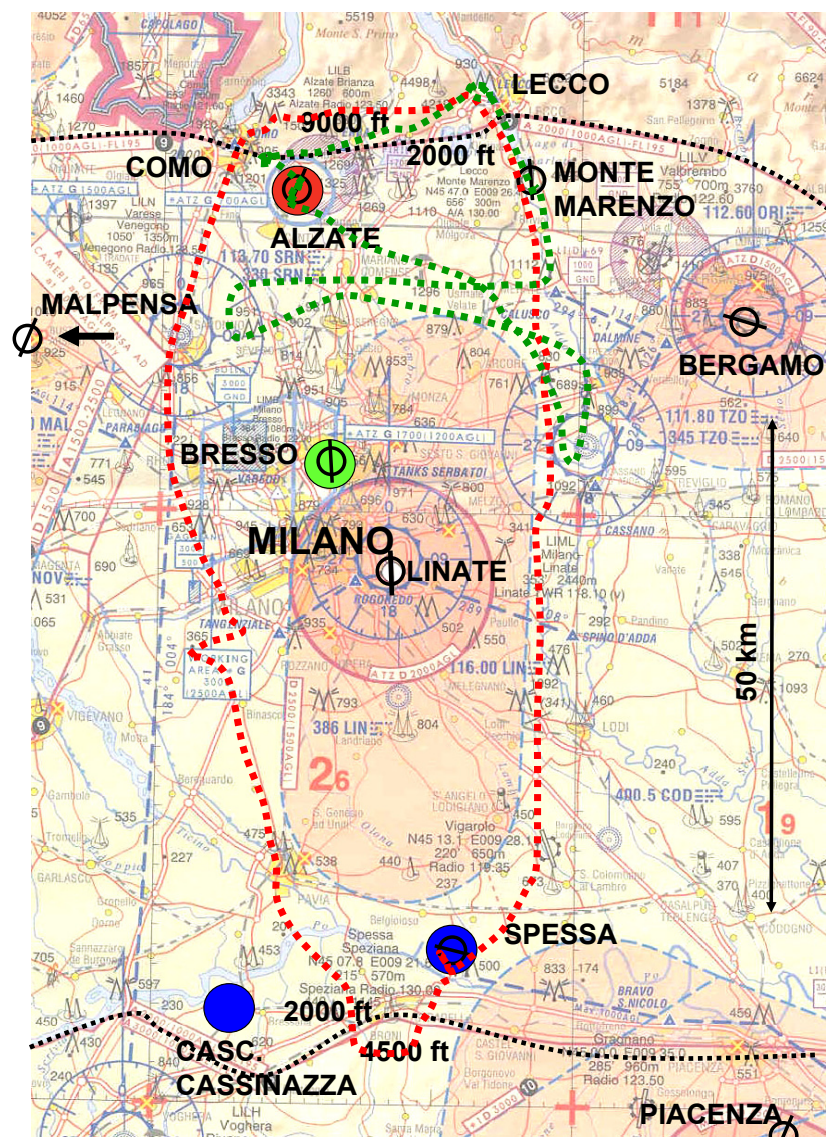

Fig. 1. The map shows the research area of Milano from the pilots view (with airspace information). Ground stations are marked with colored dots, airports/airfields with circles and landing strip indicator. Larger airports in the vicinity with extended control zones are Malpensa, Linate, Bergamo. The black dotted lines in the north and the south indicate the boundaries of the $2000 \mathrm{ft}(600 \mathrm{~m}$ above $\mathrm{m}$ a.s.l) allowed airspace for flights under visual flying rules. In the north up to $9000 \mathrm{ft}$ maximum altitude are allowed, in the south $4500 \mathrm{ft}$ above sea level. The reddish marked areas are the approach zones for the larger airports, Airspace D, with additional flying restrictions also in low altitudes. Marked with green dots is a typical flight pattern in 2002 operating from Monte Marenzo and in red for 2003 from Spessa.

Within the whole western Po-Valley, flights under visual flying rules (VFR) are allowed below a level of $2000 \mathrm{ft} \mathrm{m}$ a.s.l only. Above this level, due to the high density of airports and commercial traffic, the airspace is designated as an airspace category which is restricted solely to instrumental flying rules. Since microlight aircraft are not allowed to operate within this airspace, vertical profiles were limited to the northern and southern edges of the valley. In the area of Lecco and Como, approximately $10 \mathrm{~km}$ north of the ground station Alzate, it was possible to climb up to $9000 \mathrm{ft}$ a.s.l. $(\sim 2700 \mathrm{~m})$ In the south the mountain slopes are less steep and hence the upper limit of the permitted airspace was $4500 \mathrm{ft}$ a.s.l. $(\sim 1400 \mathrm{~m})$.
Although both campaigns were performed during the summer or early fall the weather patterns were quite different. The first campaign, lasting from the end of July until mid August was characterized by more humid and hazy conditions with a high frequency of mid elevation cumulus clouds between $\sim 1000 \mathrm{~m}$ and $\sim 3000 \mathrm{~m}$ above ground. The second campaign, lasting from September until early October gave typically dry and cloud free conditions. Hence, due to low visibility and a high chance of thunderstorms in 2002, most of the flights were done in the close vicinity of Lecco and Como, north of Milano. Only one flight was performed leading to the south east of Milano. Due to the more favourable weather in 2003 the typical flight pattern of the second campaign included a low elevation $(\sim 400-500 \mathrm{~m}$, upper limit $2000 \mathrm{ft}$ a.s.1.) circle around Milano avoiding the airport zone of the city airport of Linate (shaded airspace D, Fig. 1). Vertical profiles, ascents above Lecco up to $3000 \mathrm{~m}$ a.s.l. and descents close to Como back to about $300 \mathrm{~m}$ a.s.l. were also undertaken. Occasional comparison flights also passed the ground site of Alzate at very low elevation flying a missed approach to the airfield. In Fig. 1, flight patterns for $18 \mathrm{Au}-$ gust 2002 (green dotted line) and 18 September 2003 (red dotted line) are given as examples.

The city location Bresso, which is situated on a small airfield just south of the northern motorway belt around Milano, is the most affected one by direct local emissions. Here, local traffic emissions, occasionally directly beneath the site are the main influence (Hak et al., 2005). The other stations were located in less traffic affected areas. For example Alzate is located at least $10 \mathrm{~km}$ from main motorways at the edge of a glider airfield near a small village. Cascina Cassinazza is in an agricultural area south of the river Po while Spessa is also located on a small airfield within an agricultural rice growing area. The northern part of the Po-Valley between Milano, Como and Lecco is mostly covered by mixed forests while in the southern half only small patches of forest are left. Here the main agricultural activity is rice production. In contrast to the north, the south contains several plantations of poplar which might be important local sources of HCHO precursors. Population density and traffic is by far higher in the north than in the south. Along the northern rim of the valley, the motorway from Milano to Venezia and along the motorways from Milano to Como is a belt of highly concentrated small to medium sized industries, including also some chemical industry. Heavy industry (steel production) can be found $80 \mathrm{~km}$ to the east of Milano in Brescia. The closest airports are Malpensa, $30 \mathrm{~km}$ northwest, Bergamo, $30 \mathrm{~km}$ northeast, Linate, $5 \mathrm{~km}$ east and Piacenza, $50 \mathrm{~km}$ southeast. The centre of the Po-Valley is mainly characterized by agriculture while another chain of midsize towns line up on the southern rim from Alessandria to Bologna (Piacenza, Reggio Emilia etc). Several motorways also cross the valley.

Differences in land use and population are also reflected in the regional emission patterns. The main source of $\mathrm{NO}_{\mathrm{x}}$, VOC and ozone precursors are to be found at the core of 
the city of Milano and along the main motorways. The population of the inner city of Milano has been shrinking for more than a decade with more people moving to the north into the prealpine hills. Overall, however, the population in the greater Milano area is increasing.

After harvesting, the remaining straw on the rice fields is burnt to prevent pests in the rice monoculture. Clearly visible and well localized sources for $\mathrm{HCHO}$ and small particles are these numerous biomass fires. This anthropogenic fire activity is higher in the south than in the north and contributes to overall $\mathrm{HCHO}$ mixing ratios with a diurnal variation similar to biogenic emissions.

Due to the holiday season and hence a strong reduction of traffic in the first two weeks of August 2002, the pollution levels in Milano were low, but after 12 August they were moderate. In September 2003, a week of high pressure and high anthropogenic activity yielded high pollution levels.

\section{Results}

\subsection{Ground based}

Details of the intercomparison week, such as the formaldehyde mixing ratios of all participating instruments, the weather patterns, local instrument setup of Bresso and the site of the comparison week are described in Hak et al. (2005). General and local meteorological conditions for both campaigns are described in Liu et al. (2007a, b). Here, further data are included both from Bresso and the two sites south of Milano, as well as a discussion of typical diurnal patterns. All stations in both campaigns showed a pronounced diurnal variation of $\mathrm{HCHO}$ on dry days without precipitation, with maxima during the late morning and minima during the night hours. The complete data set is shown in Fig. 3 for 2002 and 2003. Typical diurnal variations at all sites under clean, moderate and high pollution situations are shown in Fig. 4.

After the comparison week in 2002, HCHO levels rapidly decreased in the city in early August due to the main two summer holiday weeks in Italy and slightly increased again after 12 August. These trends can be attributed to changes in local emissions as traffic and industrial emissions during this time are significantly reduced. After 15 August, anthropogenic activities rapidly return to their usual intensity. The northern and southern remote sites were less affected and showed more or less consistent levels of HCHO throughout the campaign duration. An exception of this is a period of three very clean days from 10 to 12 August, which occurred during a frontal passage that included a föhn event. Föhn events are characterized by dry and clean catabatic descending air. Most water soluble gaseous compounds are scavenged in the orographic and precipitating clouds on the upwind side of the mountains. This weather situation in the
Po-Valley is accompanied by strong northerly winds, high visibility, clear skies and very low pollution levels.

It is interesting to note that the diurnal $\mathrm{HCHO}$ maxima in 2002 were higher in the south than in the north. In 2003, the campaign began with variable conditions followed by a photochemically active period of about one week from 15 to 22 September with a pronounced increase of the nocturnal minima at the two northerly stations. Although the maxima in the south in this week were also the highest during the campaign, the nocturnal minima remained at a low level.

As the emission situation in the south is very similar for both locations, the two southern locations are considered to be comparable in this respect. There is no obvious reason for different emissions of $\mathrm{HCHO}$ and its precursors in the vicinity of the two locations. Weather patterns and local anthropogenic emissions are however reflected in the HCHO daytime variability and nocturnal minimum levels (see Fig. 3). Clear and dry days always show a pronounced diurnal variability at all sites that were not directly affected by local emissions. Days with changing airmasses due to frontal passages, that often brought also rain, do not show distinct diurnal patterns. During episodes with high photochemical activity, temperatures, radiation intensity and emissions or pollution the amplitude of the diurnal variability can reach up to $4 \mathrm{ppb}$, for example, 12-20 September 2003. The nighttime background values increase day by day within and in the vicinity of the densely populated areas by up to $5 \mathrm{ppb}$. This is shown in Fig. 3 for Bresso and Alzate in 2003. The highest diurnal maxima were detected also in Spessa in the 2003 campaign but the nocturnal baseline enhancement was not evident. Wind speeds close to the mountain slopes in Alzate were below $3 \mathrm{~m} / \mathrm{sec}$ during high pressure episodes. A regular change of the wind direction was observed at this station indicating some thermally driven advective exchange pattern north of Milano (Liu et al., 2007a; Steinbacher et al., 2005a). In Bresso, which is close to the main anthropogenic sources, typical diurnal patterns in contrast to that observed at the other stations were less pronounced. High peak levels were observed throughout the day depending on the local advection. Low and moderate polluted days show a variability of about $2-3 \mathrm{ppb}$ and nighttime background values between 0.5 and $2 \mathrm{ppb}$. Nighttime minima were observed at all stations between 04:00 and 06:00 UTC. In 2002, which was characterized by low and moderate pollution levels, no significant differences between the north and the south in nighttime minima were observed.

To identify typical diurnal variations in different pollution levels, three episodes without rainfall and frontal passages were selected from the whole data set and the average diurnal variability was calculated for at least five consecutive days. The cleanest conditions were found in the first week of August 2002, moderate conditions from 13 to 19 August and polluted conditions in 2003 from 15 to 22 September. The diurnal variations for these three different episodes, for the three measurement sites are shown in Fig. 4a-i. Left to right 
panels show clean to heavily polluted conditions. Top to bottom panels move from the north to the south. The figure also contains the model results calculated from two hour intervals for Bresso and Alzate with diurnal variations from the same days as the measurements, as published in Liu et al. (2007a, b).

Within the diurnal variations, some general features can be observed. The diurnal minimum was always observed between 04:00 and 06:00 UTC which increased by 2-3 ppb within $4 \mathrm{~h}$ at all stations thereafter. Differences in the emission or pollution intensity are reflected in either enhanced background levels or the slope of morning $\mathrm{HCHO}$ production rates. With additional anthropogenic emissions, the morning production rates increased. In the city the mixing ratios increased by more than twice $(1.5-2 \mathrm{ppb} / \mathrm{h})$ that of the other two sites $(\sim 0.4-0.7 \mathrm{ppb} / \mathrm{h})$ north and south of the city. With increasing anthropogenic activity, also the amplitude of the diurnal variability between maximum and minimum increases by about $0.5-1 \mathrm{ppb}$ with secondary afternoon or early evening peaks also evident. In Bresso, a midnight peak with a magnitude of $\sim 1.5 \mathrm{ppb}$ was observed. This city location shows a similar pattern to that observed in highly polluted conditions of Mexico City (De Gouw et al., 2009). After the main peak in the morning, afternoon $\mathrm{HCHO}$ mixing ratios decrease rapidly and drop down to values close to the nighttime minima, followed by a short secondary late evening or midnight maximum (Fig. 4f).

The diurnal patterns of $\mathrm{HCHO}$ are dominated by local processes like vertical mixing and the evolution of the planetary boundary layer, as well as the temporal evolution of emissions. The rapid decline and the shape of the morning peak in Mexico (De Gouw et al., 2009) was attributed to dilution after the breakup of the morning inversion layer. This is consistent with the usual development of the PBL beginning with a nighttime inversion at $\sim 200 \mathrm{~m}$ which rises up to $>1500 \mathrm{~m}$ above ground in the daytime. During the day photolysis leads to a fast reduction of $\mathrm{HCHO}$ levels. As $\mathrm{HCHO}$ is rapidly photolysed with lifetimes of about $2 \mathrm{~h}$ during summer conditions (Behning and Wahner, 1998), high concentrations of formaldehyde during noon hours indicate strong sources in the vicinity. This occurs at the remote sites during the day, where maximum $\mathrm{HCHO}$ production from biogenic precursors during the noon hours is assumed.

At the city location Bresso, the direct impact of fresh emissions can be identified. The peaks are strongly dependent on wind direction and reflect the main emission pathways from traffic in the vicinity. For a more detailed analysis of this period see Hak et al. (2005). In the Po-Valley the mixed layer is expected to be $\sim$ at $200 \mathrm{~m}$ above ground in the early morning and at $\sim 800-1200 \mathrm{~m}$ at noon which would lead to a dilution of fresh morning emissions by a factor of four to five. Probably the meteorology coupled mixing here is less extreme, compared with Mexico and the break up of the morning inversion begins, before the morning rush hour in the city is terminated. Bresso had the highest mixing ratios reaching up to $15 \mathrm{ppb}$ during episodes with low wind speeds. The high variability and strong dependence from local sources is reflected in the smoothing and reduction of the maxima over a five day average to a level of $\sim 9 \mathrm{ppb}$.

The two remote stations show a secondary maximum in the afternoon under moderate to heavily polluted conditions close to the time of the evening rush hour. The faster morning increase due to traffic emissions is not as significant as in the city. In the north, clean and moderate conditions are very similar, while in the polluted episode, the morning rise was 1.5 times as fast (from $0.4 \mathrm{ppb} / \mathrm{h}$ to $0.6 \mathrm{ppb} / \mathrm{h}$ ). In the south, the polluted week in 2003 gave a morning ascent that was even lower than for cleaner episodes $(0.4$, respectively $0.7 \mathrm{ppb} / \mathrm{h}$ ). A major difference between both remote sites was found in the most polluted week in Alzate, where the nighttime concentrations were comparable to those measured directly in the city.

Within previous campaigns (PIPAPO, Neftel et al., 2002), a strong transport system was observed between Milano and the mountain area north of Milano (Triangolo Lariano) which transported air from the flat polluted valley effectively into the mountains. Although sometimes visible in Alzate with regular changing wind directions in the diurnal cycle, during either of the FORMAT campaigns this wind system was not dominating. Winds were low to moderate. Strong valley wind systems as in PIPAPO (Neftel et al., 2002) were not observed in the two main valleys of Lago di Como and Lago di Lecco. The Monte Marenzo airfield is situated in the valley just south of Lecco. The general trend in $\mathrm{HCHO}$ values during the high pressure episode (15 to 22 September) could be due to either an effective wind system, which was not observed from the airborne measurements, or from similar anthropogenic emissions in the city and/or the highly industrialized area north of the city (see Fig. 2). Such increasing nighttime HCHO levels were not visible in the agriculturally dominated south.

\subsection{Airborne}

In the first campaign (2002) flights were mostly performed north and east of Milano. They typically aimed at the investigation of the vertical profile of $\mathrm{HCHO}$ and at comparisons with the ground site at Alzate. Flights in the second campaign operating from the airfield of Spessa gave a more complete picture of the three dimensional distribution of $\mathrm{HCHO}$ in the Po-Valley. On one day a flight further east was possible for intercomparison with the Partenavia which measured power plant plumes in the eastern Po-Valley (Wang et al., 2005) and for vertical profiles located more towards the centre of the valley. This is only possible in the airspace east of the line from Brescia to Cremona and requires to remain clear of the Milano restricted airspace. The horizontal distributions in the well mixed boundary layer a few hundred meters above the ground during the day were generally in agreement with the ground based measurements. Several 

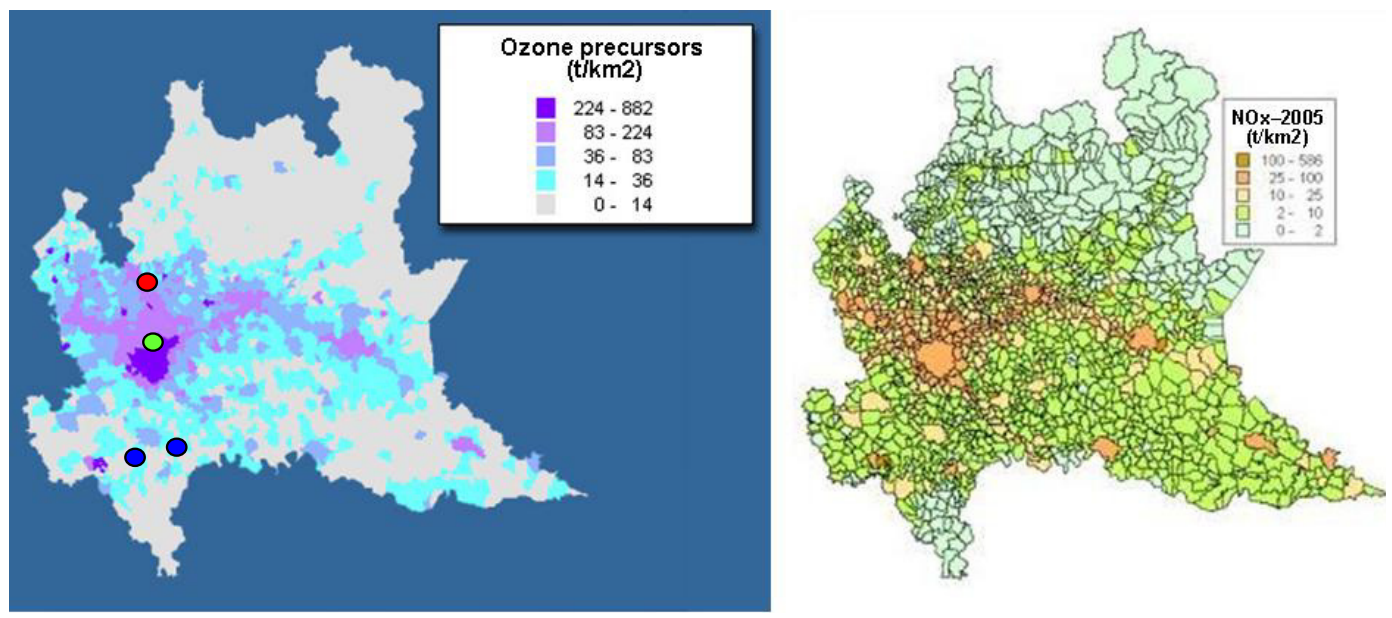

Fig. 2. Ozone precursor and $\mathrm{NO}_{\mathrm{x}}$ emissions in the region Lombardia, the Milano area is the western half of the picture. The ground sites are marked in the left panel. The main motorways are clearly marked by the high $\mathrm{NO}_{\mathrm{x}}$ emissions. (http://www.arpalombardia.it/qaria/ doc_MappeEmissione.asp).
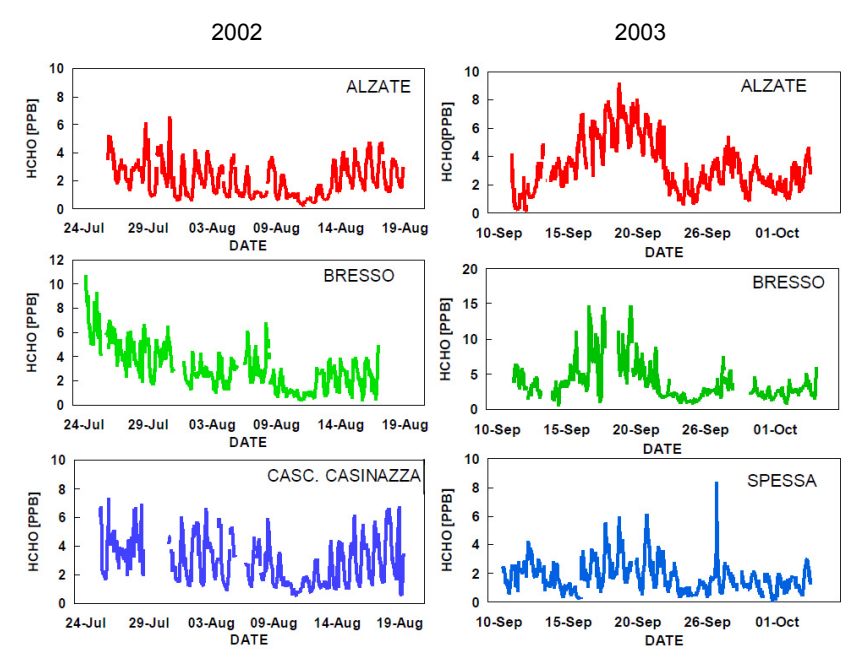

Fig. 3. half hour average concentrations of $\mathrm{HCHO}$ at the three sites in the Po-Valley, Alzate in red (north) Bresso, green (Milano center) and Casinazza /Spessa, blue, (south). Note the different mixing ratio scales at Bresso.

flyby maneuvers over Alzate airfield resulted in a maximum deviation of airborne and ground instruments by less than $300 \mathrm{ppt}$ at ambient levels between 3 and $5 \mathrm{ppb}$. Horizontally variability within $\sim 30 \mathrm{~km}$ south of Como and Lecco of up to $30 \%$ was observed without a significant typical local pattern. Special individual sources of $\mathrm{HCHO}$ in the agricultural area in the south were identified as the frequent burning of biomass. Flying directly through the fire plumes at low elevation, gave measurements of formaldehyde with peak levels of up to $15 \mathrm{ppb}$ on a background of $\sim 4 \mathrm{ppb}$. However, the residence time in the plume was only a few seconds, as detected by the fast aerosol counter which indicated particle numbers $>40000 / \mathrm{cm}^{3}$. As the $\mathrm{HCHO}$ instrument has a slow response time of $90 \mathrm{~s}$, this would correspond to peak levels of about 35 to $40 \mathrm{ppb}$ in the plume (Junkermann and Burger, 2006). Injection of high concentrations of HCHO into the well mixed planetary boundary layer by these agricultural activities increase the regional $\mathrm{HCHO}$ mixing ratios. Since the diurnal cycle of fire activity is very similar to biogenic precursor emissions in otherwise remote areas, this does not allow the discrimination between the sources.

The meteorological conditions during the two campaigns resulted in different vertical distributions of HCHO. During both campaigns, the vertical distribution of $\mathrm{HCHO}$ was controlled by vertical mixing processes of different time scales. The planetary boundary layer (PBL) during the noon hours was always well mixed as a result of rapid turbulent mixing within less than half an hour, compared to the photochemical time constants of hours for decomposition reactions. Above the PBL, significant formaldehyde levels were observed only in the presence of convective clouds that pump planetary boundary layer air into the free troposphere by cloud venting. During this process, PBL air is transported through the cloud and is subject to wet chemical processes that are expected remove $\mathrm{HCHO}$ from the air to the liquid phase (Lelieveld and Crutzen, 1990). Part of HCHO can then react in the liquid phase to form hydroxymethanesulfonate, HMS, a complex formed from HCHO and S(IV) (Rao and Collet, 1995). It can also form formic acid. Both reactions reduce $\mathrm{HCHO}$ gas phase levels within the presence of clouds (Lelieveld and Crutzen, 1990). It's not known how efficient the loss process is in the clouds as this depends on many different factors such as the residence time within the cloud, cloud microphysics and liquid phase chemistry. It may also be reversible as a result of cloud droplets evaporation. In the nonprecipitating clouds $\mathrm{HCHO}$ can survive conversion to HMS 

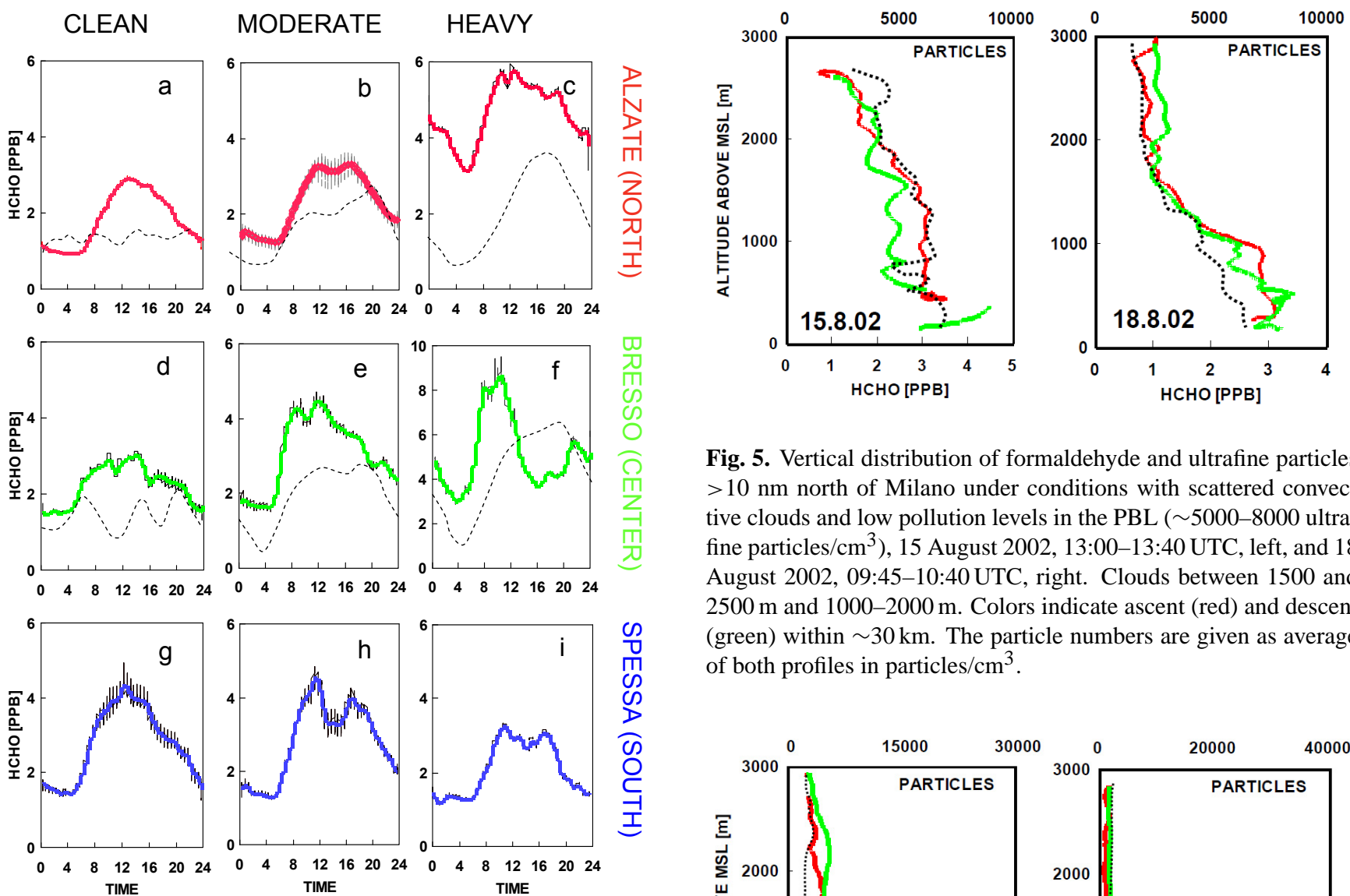

Fig. 4. (a-i): Average diurnal variations of $\mathrm{HCHO}$ at three different sites, for clean, moderate and polluted conditions, increasing pollution from left to right. A minimum of five consecutive days was used to calculate the diurnal patterns. The grey vertical bars give the variability of the underlying half hour averages. Note the larger mixing ratio scale under polluted conditions in Bresso (f). Marked as dotted lines are the model diurnal variations from Liu et al. (2007a, b) for Alzate and Bresso.

or formic acid, and consequently is released in higher elevations above the PBL. Here it contributes to enhanced HCHO concentrations in the cumulus cloud layer compared with the free troposphere. The result is a steady decline of $\mathrm{HCHO}$ mixing ratios between cloud base and cloud tops. PBL concentrations are found at cloud base, values close to the free troposphere at cloud top. This is an indication that the wet chemistry is probably not able to significantly remove $\mathrm{HCHO}$ without precipitation. Above the cloud top level $(\sim 2500$ $3000 \mathrm{~m}$ ) the HCHO concentration drops to values below 1 ppb. Examples are given in Fig. 5 for 15 August 2002, 13:00-13:40 UTC and 18, 09:45-10:15 UTC, ascents in red, descents in green. Free tropospheric mixing ratios between 0.1 and $0.5 \mathrm{ppb}$ (Kormann, 2005) were not observed within the permitted VFR (visual flying rules) altitude range, which only extended just above cloud top. Also given in Fig. 5 is the average concentration of ultrafine particles larger than $10 \mathrm{~nm}$ in particles $/ \mathrm{cm}^{3}$ as a black dotted line. Without con-
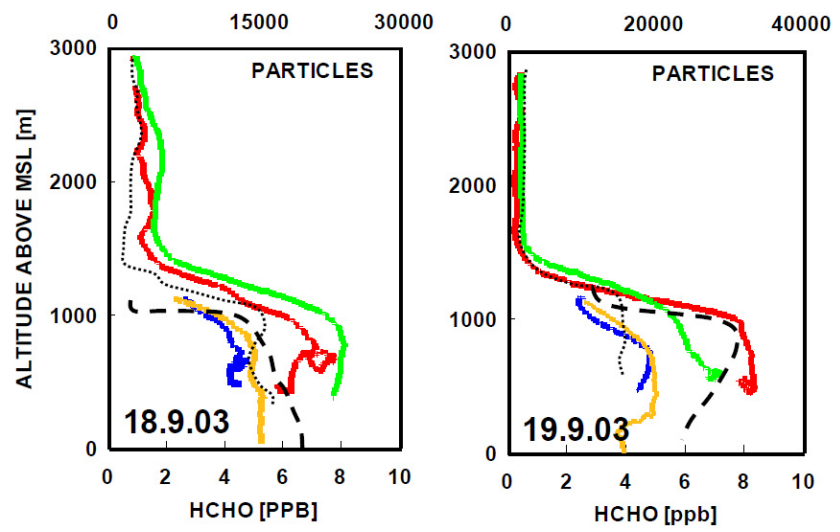

Fig. 6. Vertical profiles of formaldehyde and ultrafine particles $(>10 \mathrm{~nm})$ in the north and south of the Po-Valley under cloud free conditions, September 18, 2003, left panel, red and green profiles in the north 11:30-12:15 UTC, blue and yellow south of river Po 13.25-13:50 UTC. The right panel shows the same data for 19 September (10:50-12:40 UTC and 13:40-14:00 UTC). Colors indicate ascents (red and blue) and descents (green and yellow). The particle numbers are given as average of both profiles in particles $/ \mathrm{cm}^{3}$, (upper scale, dotted line north, dashed line south).

vective clouds in the campaign of 2003, the HCHO mixing ratios drop more rapidly above the upper rim of the PBL to values of approximately 200 ppt. This is concurrent with the drop in small particles and a drop in the absolute humidity. Figure 6 shows the results from vertical ascents and descents in 2003 in the north and the south of the Po-Valley on 18 September 2003, 11:50-12:40 UTC (north) and 13:4014:00 UTC (south) and 19 September, 11:25-12:15 UTC and 13:25-13:50, respectively. Red and blue lines are ascents, 
while green and orange ones are descents. The concentration of ultrafine particles $>10 \mathrm{~nm}$ is also given as dotted lines for the north and dashed lines for the south. Vertical mixing reaches higher altitudes in the north than in the south. The clear separation between the planetary boundary layer and the free troposphere indicates that the main fraction of the $\mathrm{HCHO}$ is located in the PBL as soon as transport processes are terminated. Although the correlation between ultrafine particles and $\mathrm{HCHO}$ in the vertical distributions is obvious, there was no observable correlation between absolute particle numbers, the distribution of particles in fine and ultrafine mode, and $\mathrm{HCHO}$ mixing ratios.

A difference in the mixing height between north and south (Wiegner et al., 2006) can be due to a number of different processes. In the case of a pronounced valley wind system ("alpine pumping" Weissmann et al., 2005), a variability in the upper boundary of the PBL results from transport processes over tilted terrain. Alzate is situated $385 \mathrm{~m}$ above sea level, Spessa at $70 \mathrm{~m}$. The thickness of the well mixed planetary boundary layer is also a result of the energy conversion processes on the ground and thus on the albedo of the surface (Junkermann et al., 2009). It can also be affected by heat island effects of Milano (Weissmann et al., 2005) or by local thermal activity at the foothills along the northern rim of the valley. A real city plume, as observed in PIPAPO, could significantly increase the concentrations to the north of Milano. Given the variability and the uncertainties of the emissions from anthropogenic and natural emissions in the area, and missing detailed characterization of the wind field from the experimental data, a clear city plume situation could not be deduced. However, the model calculations and aircraft measurements presented in Liu et al. (2007a) indicate a plumelike situation at least for 17 August 2002. Above the main emission area northwest of Milano and within the high pollution episode in 2003, the mixing ratios are higher in the north than in the south.

\section{Model comparison}

Comparing published model calculations for the two FORMAT campaigns with the experimental data shows pronounced differences (see Fig. 4a-i). Model calculations for the FORMAT campaigns were performed by Liu et al (2007a, b) using two different models: NILU RTCM (Regional Chemical Transport Model) (Flatoy and Hov, 1996) for 2002 and CAMx (Comprehensive Air Quality Model) (Environ, 2004) for the 2003 campaign. Both models were used and compared in Liu et al. (2007a, b) for only the city location of Bresso and the northern site of Alzate although the model domains also include the two southern sites. In the 2003 modelling activity, a more easterly model area was introduced which was considered to be free of local Milano pollution levels instead of the southerly site at the river Po. The model grid size for the NILU RTCM is $15 \times 15 \mathrm{~km}$ with up to 30 vertical layers. CAMx was applied with a nested version and has $27 \times 27 \mathrm{~km}$ for the coarse resolution and $9 \times 9 \mathrm{~km}$ in the fine grid with ten vertical layers up to $4000 \mathrm{~m}$ above ground level. In the calculations for 2002, we observed a correlation between measurements and the model, both in the diurnal variability between maxima and minima, less precise in the timing of the diurnal pattern. The model often shows an additional late evening peak in the HCHO mixing ratio which is concurrent with a similar peak in the modelled and measured CO. However, it does not generate a similar traffic emission related peak in the morning. The duration of both late evening peaks is about two hours.

The horizontal distribution in both models gives higher mixing ratios in the north than in the south. The opposite trend with higher mixing ratios in the south, observed in the experimental 2002 data, could not be confirmed. According to the model, values about 30-50 percent lower compared with the experimental results would be expected for the southerly locations.

The 2003 calculations were performed for three domains within the Po-Valley: the centre of Milano, the northern station of Alzate and an area east of Milano (area 3, Liu et al., 2007b). The latter was assumed to be uninfluenced by emissions from Milano. This area is similar in agricultural land use to the southern location Spessa, though the surroundings of Spessa have an even higher fraction of rice monoculture. Although making use of a better spatial resolution than the NILU RTCM model, the CAMx model performed similarly in the prediction of the diurnal variability but with a higher diurnal amplitude. It was also worse in predicting the timing of the diurnal patterns. The timing of HCHO maxima and minima is shifted further to the evening, although the model diurnal patterns of ozone and nitrogen oxides were in good agreement with the experiment. The CAMx model produced an even stronger evening peak than the NILU RTCM in formaldehyde and was not able to match the morning ascent in mixing ratios properly. Also the patterns and the maximum amplitude in more remote areas, not affected by Milano anthropogenic emissions (e.g. area 3 east of Milano, Liu et al., 2007b) are underestimated, compared to the agricultural environment at Spessa. As the model does not match the morning rise of $\mathrm{HCHO}$ mixing ratios it cannot be expected that the experimentally observed anthropogenic emission dependencies in the diurnal cycles are clearly observable in the model.

For the vertical distributions model results are only available for the 2002 campaign. The agreement with the measured vertical distributions is better than with horizontal distributions. As the model strongly suppresses exchange between the planetary boundary layer model profiles show a more pronounced step function of mixing ratios at the upper rim of the PBL similar to what has been observed in the more stable conditions such as in 2003. 


\section{Summary and conclusions}

Formaldehyde measurements have been performed in two campaigns in 2002 and 2003 during summer conditions in one of Europe's most polluted areas. Three different ground based sites, "upwind", in the centre and "downwind" of the Milano metropolitan area were used. Measurements by a small aircraft operating on a regional scale and climbing up to the free troposphere were also conducted. Humid and cloudy conditions as well as dry high pressure situations and also a period with reduced anthropogenic emissions were investigated. Formaldehyde mixing ratios on the ground showed a pronounced diurnal variability at all three sites with a significant signature of local anthropogenic production only in the centre of Milano, where mixing ratios up to $15 \mathrm{ppb}$ were occasionally observed. Both locations outside the city exhibited diurnal patterns, typical for compounds generated by secondary photochemical reactions. The more remote southerly agricultural locations had surprisingly high HCHO mixing ratios. These were up to a factor of two higher than calculated by the two regional chemistry transport models which assumed a low wind speed situation with slow transport of pollution from Milano into the foothills of the Alps. These high formaldehyde levels would require either additional biogenic precursors or anthropogenic activities with a similar diurnal pattern. Biomass burning of rice straw at the end of the growing season could be identified as one important anthropogenic source of small particles and formaldehyde from frequent distributed local sources. These follow a similar diurnal pattern as biogenic emissions. Differences between model and experiment are most probably due to the uncertainties in the emission inventories, especially in the diurnal cycle and magnitude of direct anthropogenic emissions.

Edited by: J. W. Bottenheim

\section{References}

Environ International Corporation: Environ User's Guide: Comprehensive Air Quality Model With Extensions (CAMx), version 4.10, Novato, CA, www.camx.com, 2004.

Eom, I.-Y., Li, Q., and Dasgupta, P.: Robust hybrid flow analyzer for formaldehyde, Env. Sci. Technol., 42, 1221-1226, 2008.

Fuentes, J. D., Wang, D., Bowling, D. R., Potosnak, M., Monson, R. K., Goliff, W. S., and Stockwell, W. R.: Biogenic Hydrocarbon Chemistry within and Above a Mixed Deciduous Forest, J. Atmos. Chem., 56, 165-185, 2007.

Garcia, A. R., Volkamer, R., Molina, L. T., Molina, M. J., Samuelson, J., Mellqvist, J., Galle, B., Herndon S. C., and Kolb, C. E.: Separation of emitted and photochemical formaldehyde in Mexico City using a statistical analysis and a new pair of gas-phase tracers, Atmos. Chem. Phys., 6, 4545-4557, 2006, http://www.atmos-chem-phys.net/6/4545/2006/.

de Gouw, J. A., Welsh-Bon, D., Warneke, C., Kuster, W. C., Alexander, L., Baker, A. K., Beyersdorf, A. J., Blake, D. R., Cana- garatna, M., Celada, A. T., Huey, L. G., Junkermann, W., Onasch, T. B., Salcido, A., Sjostedt, S. J., Sullivan, A. P., Tanner, D. J., Vargas, O., Weber, R. J., Worsnop, D. R., Yu, X. Y., and Zaveri, R.: Emission and chemistry of organic carbon in the gas and aerosol phase at a sub-urban site near Mexico City in March 2006 during the MILAGRO study, Atmos. Chem. Phys., 9, 3425-3442, 2009,

http://www.atmos-chem-phys.net/9/3425/2009/.

Hak, C., Pundt, I., Trick, S., Kern, C., Platt, U., Dommen, J., Ordóñez, C., Prévôt, A. S. H., Junkermann, W., Astorga-Lloréns, C., Larsen, B., Mellqvist, J., Strandberg, A., Yu, Y., Galle, B., Kleffmann, J., Lörzer, J. C., Braathen, G. O., and Volkamer, R., Intercomparison of four different in-situ techniques for ambient formaldehyde measurements in urban air, Atmos. Chem. Phys., 5, 2881-2900, 2005,

http://www.atmos-chem-phys.net/5/2881/2005/.

Heckel, A., Richter, A., Tarsu, T., Wittrock, F., Hak, C., Pundt, I., Junkermann, W., and Burrows, J. P., MAX-DOAS measurements of formaldehyde in the Po-Valley, Atmos. Chem. Phys., 5, 909918, 2005, http://www.atmos-chem-phys.net/5/909/2005/.

Junkermann, W.: An ultralight aircraft as platform for research in the lower troposphere: system performance and first results from radiation transfer studies in stratiform aerosol layers and broken cloud conditions, J. Ocean.\& Atm. Techn., 18, 934-946, 2001.

Junkermann, W. and Stockwell, W. R.: On the budget of photooxidants in the marine boundary layer of the tropical South Atlantic, J. Geophys. Res., 104, 8039-8046, 1999.

Junkermann, W. and Burger, J. M.: A new portable instrument for continuous measurement of formaldehyde in ambient air, J. Atmos. Ocean. Technol., 23, 38-45, 2006.

Junkermann, W., Hacker, J. M. H., Lyons, T., and Nair, U.: Land use change suppresses precipitation, Atmos. Chem. Phys., 9, 65316539, 2009.

Kormann, R., Fischer, H., de Reus, M., Lawrence, M., Brühl, C., von Kuhlmann, R. Holzinger, R., Williams, J., Lelieveld, J., Warneke, C., de Gouw, J., Heland, J., Ziereis, H., and Schlager, H.: Formaldehyde over the eastern Mediterranean during MINOS: Comparison of airborne in-situ measurements with 3Dmodel results, Atmos. Chem. Phys., 3, 851-861, 2003, http://www.atmos-chem-phys.net/3/851/2003/.

Lei, W., Zavala, M., deFoy, B., Volkamer, R., Molina, M. J., and Molina, L. T.: Impact of primary formaldehyde on air pollution in the Mexico City Metropolitan Area, Atmos. Chem. Phys., 9, 2607-2618, 2009,

http://www.atmos-chem-phys.net/9/2607/2009/.

Lelieveld, J. and Crutzen, P. J.: Influences of cloud photochemical processes on tropospheric ozone, Nature, 343, 227-233, doi:10.1038/343227a0, 1990.

Lin, C.-Y., Chen, F., Huang, J. C., Chen, W. C., Liou, Y. A., Chen, W. N., and Liu, S. C.: Urban heat island effect and its impact on boundary layer development and land-sea circulation over northern Taiwan, Atmos. Environ., 42, 5635-5649, 2008.

Liu, L.,Andreani-Aksoyoglu, S., Keller, J., Ordóñez, C., Junkermann, W., Hak, C., Braathen, G. O., Reimann, S., Astorgallorens, C., Schultz, M., Prévôt, A. S. H. and Isaksen, I. S. A., A photochemical modelling study of ozone and formaldehyde generation and budget in the Po basin, J. Geophys. Res., 112, D22303, doi:10.1029/2006JD008172, 2007a.

Liu, L., Flatøy, F., Ordóñez, C., Braathen, G. O., Hak, C., Junker- 
mann, W., Andreani-Aksoyoglu, S., Mellqvist, J., Galle, B., Prévôt, A. S. H., and Isaksen, I. S. A.: Photochemical modelling in the Po basin with focus on formaldehyde and ozone, Atmos. Chem. Phys., 7, 121-137, 2007b,

http://www.atmos-chem-phys.net/7/121/2007/.

Neftel, A., Spirig, C., Prévôt, A. S. H., Furger, M., Stutz, J., Vogel, B., and Hjorth, J.: Sensitivity of photooxidant production in the Milan Basin: An overview of results from a EUROTRAC-2 Limitation of Oxidant Production field experiment, J. Geophys. Res., 107(D22), 8188, doi:10.1029/2001JD001263, 2002.

Possanzini, M., Di Palo, V., and Ceccinato, A.: Sources and photodecomposition of formaldehyde and acetaldehyde in Rome ambient air, Atmos. Environ., 36, 3195-3201, 2002

Rao, X. and Collett, J. L.: Environ. Sci. Technol., 29, 1023-1031, doi:10.1021/es00004a024, 1995.

Slemr, J., Junkermann, W., and Volz-Thomas, A.: Temporal variations of Tropospheric $\mathrm{CH}_{2} \mathrm{O}$ at a Rural site in Southern Germany, Atmos. Environ., 30, 3667-3676, 1996.

Steinbacher, M., Dommen, J., Ordonez, C., Reimann, S., Grübler, F. C., Staehelin, J., and Prevot, A. S. H.: Volatile Organic Compounds in the Po Basin. Part A: Anthropogenic VOCs, J. Atmos. Chem., 51, 271-291, doi:10.1007/s10874-005-3576-1, 2005a.

Steinbacher, M., Dommen, J., Ordonez, C., Reimann, S., Grübler, F. C., Staehelin, J., Andreani-Aksoyoglu, S., and Prevot, A. S. H.: Volatile Organic Compounds in the Po Basin. Part B: Biogenic VOCs, J. Atmos. Chem., 51, 293-315, doi:10.1007/s10874-0053577-0, 2005b.
Wang, P., Richter, A., Bruns, W., Burrows, J. P., Heue, K.-P., Wagner, T., Platt, U., Pundt, I., and Junkermann, W.: Airborne multiaxis DOAS measurements of tropospheric $\mathrm{SO}_{2}$ plumes in the Povalley, Italy, Atmos. Chem. Phys., 5, 2017-2045, 2005, http://www.atmos-chem-phys.net/5/2017/2005/.

Weissmann, M., Braun, F. J., Gantner, L., Mayr, G. J., Rahm, S., and Reitebuch, O.: The Alpine Mountain-Plain Circulation: Airborne Doppler Lidar Measurements and Numerical Simulations, Mon. Weather Rev., 133, 3095-3109, 2005.

Wiegner, M., Emeis, S., Freudenthaler, V., Heese, B., Junkermann, W., Münkel, C., Schäfer, K., Seefeldner, M., and Vogt, S.: Mixing layer height over Munich, Germany: Variability and comparisons of different methodologies, J. Geophys. Res., 111, D13201, doi:10.1029/2005JD006593, 2006.

Wisthaler, A., Apel, E. C., Bossmeyer, J., Hansel, A., Junkermann, W., Koppmann, R., Meier, R., Müller, K., Solomon, S. J., Steinbrecher, R., Tillmann, R., and Brauers, T.: Technical Note: Intercomparison of formaldehyde measurements at the atmosphere simulation chamber SAPHIR, Atmos. Chem. Phys., 8, 21892200, 2008, http://www.atmos-chem-phys.net/8/2189/2008/. 